\title{
Three centuries of Myanmar monsoon climate variability inferred from teak tree rings
}

\author{
Rosanne D’Arrigo, ${ }^{1}$ Jonathan Palmer, ${ }^{2}$ Caroline C. Ummenhofer, ${ }^{3}$ Nyi Nyi Kyaw, ${ }^{4}$ \\ and Paul Krusic ${ }^{5}$ \\ Received 18 October 2011; revised 16 November 2011; accepted 17 November 2011; published 24 December 2011.
}

[1] Asian monsoon extremes critically impact much of the globe's population. Key gaps in our understanding of monsoon climate remain due to sparse coverage of paleoclimatic information, despite intensified recent efforts. Here we describe a ring width chronology of teak, one of the first high-resolution proxy records for the nation of Myanmar. Based on 29 samples from 20 living trees and spanning from 1613-2009, this record, from the Maingtha forest reserve north of Mandalay, helps fill a substantial gap in spatial coverage of paleoclimatic records for monsoon Asia. Teak growth is positively correlated with rainfall and Palmer Drought Severity Index variability over Myanmar, during and prior to the May-September monsoon season (e.g., $r=$ 0.38 with Yangon rainfall, 0.001, n 68). Importantly, this record also correlates significantly with larger-scale climate indices, including core Indian rainfall $\left(23^{\circ} \mathrm{N}, 76^{\circ} \mathrm{E}\right.$; a particularly sensitive index of the monsoon), and the El NiñoSouthern Oscillation (ENSO). The teak ring width value following the so-called 1997-98 El Niño of the Century suggests that this was one of the most severe droughts in the past $\sim 300$ years in Myanmar. Evidence for past dry conditions inferred for Myanmar is consistent with tree-ring records of decadal megadroughts developed for Thailand and Vietnam. These results confirm the climate signature related to monsoon rainfall in the Myanmar teak record and the considerable potential for future development of climatesensitive chronologies from Myanmar and the broader region of monsoon Asia. Citation: D'Arrigo, R., J. Palmer, C. C. Ummenhofer, N. N. Kyaw, and P. Krusic (2011), Three centuries of Myanmar monsoon climate variability inferred from teak tree rings, Geophys. Res. Lett., 38, L24705, doi:10.1029/ 2011 GL049927.

\section{Introduction}

[2] Despite its profound impacts on much of the world's population, the past climate variability of the Asian monsoon system is still poorly known [Gadgil, 2003; Cook et al., 2010]. Such information is particularly scarce for the nation of Myanmar, where instrumental-based studies of monsoon climate dynamics have been extremely limited to date [Sen

\footnotetext{
${ }^{1}$ Tree-Ring Laboratory, Lamont-Doherty Earth Observatory, Earth Institute at Columbia University, Palisades, New York, USA.

${ }^{2}$ Gondwana Tree-Ring Laboratory, Canterbury, New Zealand.

${ }^{3}$ Climate Change Research Centre, University of New South Wales, Sydney, New South Wales, Australia.

${ }^{4}$ Natural Resources Division, Forest Department, Yezin, Myanmar.

${ }^{5}$ Bert Bolin Centre for Climate Research, Stockholm University, Stockholm, Sweden.

Copyright 2011 by the American Geophysical Union. 0094-8276/11/2011GL049927
}

Roy and Kaur, 2000; Sen Roy and Sen Roy, 2011]. Myanmar (previously Burma) is one of the largest countries in southeast Asia, spanning from 10 to $28.5^{\circ} \mathrm{N}$ and 92 to $101^{\circ} \mathrm{E}$ (Figure 1), and it is directly impacted by the Indian/Asian monsoon as well as convective rainfall from the Bay of Bengal [Sen Roy and Kaur, 2000]. Much of the country is classified as having pronounced wet and dry seasons linked to monsoon seasonality, in part also created by mountainous rain-shadow effects [Kondoh et al., 2004]. Regional winter and summer monsoon rainfall indices developed from stations across the country indicate considerable complexity in patterns of rainfall, particularly in summer when there is interaction of Indian and Asian monsoon components. Myanmar rainfall correlates significantly with (but is not entirely independent from) indices of the El Niño-Southern Oscillation (ENSO), Indian monsoon rainfall (e.g., All India Summer Monsoon Rainfall or AISMR; core Indian rainfall (Indian Institute of Tropical Meteorology or IITM [Parthasarathy et al., 1994]), and the Pacific Decadal Oscillation (PDO), although these relationships are spatially and seasonally variable and not very well understood [Sen Roy and Sen Roy, 2011].

[3] In order to better understand the long-term hydroclimatic variability of Myanmar and greater monsoon Asia, longer records derived from paleoclimatic archives are invaluable. Of these, tree rings [Cook and Kairiukstis, 1990] are ideal as they can be used to glean precisely-dated, annual time series dating back centuries to millennia. Despite the considerable obstacles in studying tropical tree rings due to the general lack of seasonality (except in monsoonal regions) and the difficulty in identifying suitable tree species of sufficient longevity and defined annual rings for dendrochronology, much progress has been made in the last few decades [Worbes, 2002]. A major recent advance has been the publication of a tree-ring atlas of drought variability spanning much of monsoon Asia for the past millennium (MADA [Cook et al., 2010]). The MADA dataset has revealed evidence for major droughts and other events spanning areas of monsoon Asia (e.g., Indonesia, Thailand, and Vietnam) over the past millennium [Buckley et al., 2007, 2010], which have been linked to shifts in the tropical Indo-Pacific monsoon and ENSO systems (see below). Despite this progress, however, tree-ring data coverage over isolated countries such as Myanmar is exceedingly sparse and represents a sizeable gap in tropical tree-ring coverage of past Asian monsoon variability that is missing from the MADA.

[4] Teak (Tectona grandis) is one of the most successful tree species for tropical dendroclimatology [Buckley et al., 2007; D'Arrigo and Smerdon, 2008]. It is endemic to Myanmar, but due to its great commercial value is now rapidly disappearing (e.g., http://www.ratical.org/ratville/IPEIE/ 


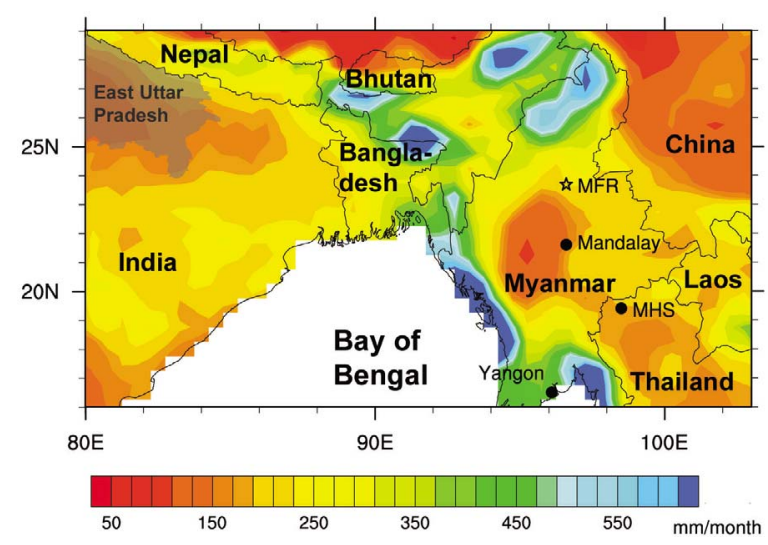

Figure 1. Map of Myanmar and adjacent southern monsoon Asia. Starred site is Maingtha Reserve Forest (MFR) teak tree-ring site north of Mandalay. Mae Hong Son (MHS) teak site in northwestern Thailand and other locations discussed in text also indicated. Background shows monthly GPCC rainfall, version 4, at 0.5 degree horizontal resolution for the period 1951-2007, averaged for the May-October months when the majority of Myanmar annual rainfall occurs. The figure shows the lower mean rainfall in central Myanmar, as discussed in the text.

Burma.html). The only other tree-ring study published for Myanmar of which we are aware is that of Pumijumnong et al. [2001] on teak. This study revealed a significant correspondence $(\sim r=0.45)$ between two preliminary living teak ring width records (one from 1834-1998 based on 21 trees, the other from 1865-1998 based on 12 trees) and transitional (wet-dry season) April rainfall in the Mandalay area of seasonally-dry central Myanmar: (correlations with Mandalay April rainfall ranged from $r=0.25-35$ ).

[5] Here we present a new tree-ring width teak chronology, also for the general region of central Myanmar, from the Maingtha Forest Reserve (Figure 1). We demonstrate that there is a significant relationship between central Myanmar teak growth and Asian monsoon climatic variability, both locally and in the core monsoon region of India and southern Asia. Findings indicate much potential for future development of reconstructions on the past hydroclimate of Myanmar and adjacent monsoon-sensitive regions based on teak.

\section{Data and Methods}

\subsection{Tree-Ring Data and Chronology Information}

[6] The Myanmar teak ring width chronology is based on raw measurements of tree-ring widths derived from 38 individual series from 20 living trees. The teak site is located in the Maingtha Reserve Forest, Kyaukme District of northern Shan State, central Myanmar (Figure 1; lat. $23^{\circ} 20 \mathrm{~N}$; long. $96^{\circ} 20 \mathrm{E}$, Compartments 28 and 30). The landscape consists of low lying hills with extensive areas of teak trees and patches of dense bamboo. The sampled area had been described (Teaknet Newsletter, 2000, http://www.teaknet.org/node/ 4810 ) as containing over 1,000 trees greater than or equal to $95 \mathrm{~cm}$ diameter breast height (DBH). There was no evidence of recent disturbance. The largest tree sampled was over $2 \mathrm{~m}$ in diameter but was later found to be hollow when cored.

[7] This record spans from 1613 to 2009 and shows evidence for interannual to multidecadal variability in monsoon rainfall during this period (Figure 2). The mean and median segment length are 278 years, an indication of the ability of this record to reflect low-frequency variability on these time scales [Cook et al., 1995]. The mean series intercorrelation (measuring year-year agreement within and between trees) and mean sensitivity (an indication of year-year changes) values are both 0.48 - positive indications of successful crossdating [Cook and Kairiukstis, 1990]. We standardized the teak record using the Arstan method [Cook, 1985], and
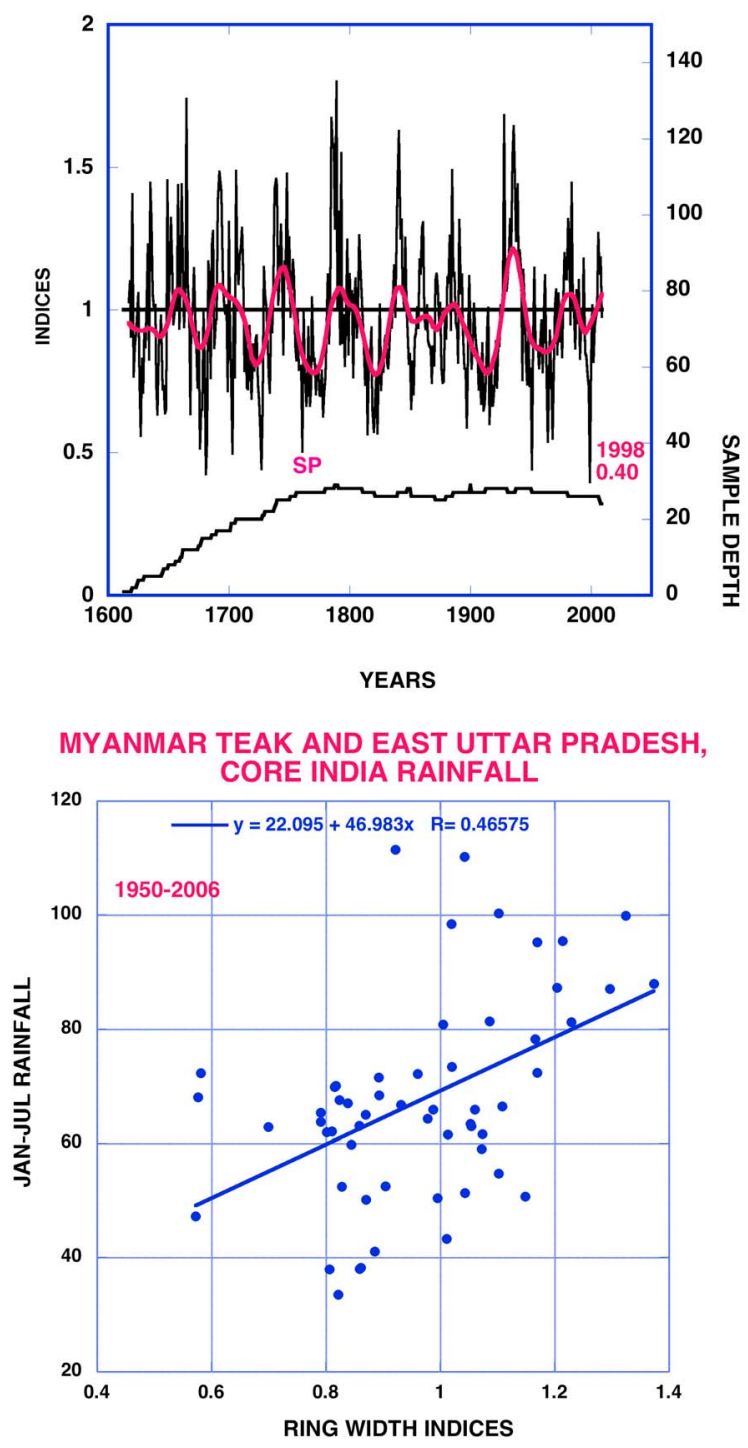

Figure 2. (top) Tree-ring width chronology of teak for central Myanmar, spanning from 1613-2009 (top graph, including sample depth; arstan chronology [Cook and Kairiukstis, 1990]). Sample depth is near its peak over much of the chronology, gradually declining prior to $\sim$ middle 1700 s. Plot labels time of Strange Parallels drought (Figure 3) and narrow ring at time of 1997-98 "El Nino of the Century". (bottom) Core Indian monsoon rainfall and teak growth (KNMI Climate Explorer, data obtained from the Indian Institute of Tropical Meteorology, IITM). Subdivision 10 of the core monsoon Indian rainfall represents the region of East Uttar Pradesh $\left(26^{\circ} \mathrm{N}, 82^{\circ} \mathrm{E}\right)$ and is significantly correlated with conditions in Myanmar, on the other side of the Bay of Bengal. 
detrended the individual ring width series using the Friedman super smoother, a data-adaptive smoothing technique that tends to retain low-frequency variance [Friedman, 1984] (alpha value setting 9). The biweight robust mean was computed for calculating the mean-value function. The expressed population signal or EPS (a measure of chronology signal strength [Wigley et al., 1984] has an overall mean of 0.90 , well above the generally accepted 0.85 cutoff except for a brief period in the mid-late $1800 \mathrm{~s}$ when it falls to just above 0.84 (Figure S1 in the auxiliary material). ${ }^{1}$ During this time period the rbar, or mean series intercorrelation, also declines (to 0.17 ; overall mean 0.28 ). Together with sample size (which remains steady back in time until $\sim$ the middle 1700 s, before which there is a gradual decline) (Figure 2), these indicators show that this chronology is a reasonably robust indicator of annual to multidecadal teak tree growth fluctuations at this site since around $\sim 1700$ [Cook and Kairiukstis, 1990]. We do, however, consider that this chronology is still rather preliminary and have not developed an actual reconstruction from these data, pending additional research.

\subsection{Climate Data}

[8] We compared the Maingtha Reserve Forest teak chronology to several local to regional climate indices. These include Historical Climate Network gridded monthly temperature data (HCN/CAMS $2 \mathrm{~m}$ analysis [Fan and van den Dool, 2008]) from 1948-present, and precipitation data from the [Beck and Grieser, 2005] Variability Analyses of Surface Temperature Observations for 1951-2000. These gridded temperature and rainfall data were analyzed over the area from $15-20^{\circ} \mathrm{N}, 95-100^{\circ} \mathrm{E}$ encompassing central Myanmar, as well as the greater south Asian region. We also examine several rainfall station records for comparison with the Myanmar teak, including for Yangon (Figure 1), one of the closest and most complete climate records for the region (Mandalay is closer to the teak site but has considerable missing data). The teak data is also compared to the gridded global monthly $2.5^{\circ} \times 2.5^{\circ}$ Palmer Drought Severity Index or PDSI, a drought metric that combines information on both temperature and moisture [Palmer, 1965; Dai et al., 2004].

[9] We also evaluate several indices of Indian monsoon rainfall and its subdivisions (IITM; http://www.tropmet.res. in/). Initial screening with the Maingtha teak indicated that we should focus on the core Indian monsoon region (CORIN, $23^{\circ} \mathrm{N}, 76^{\circ} \mathrm{E}$ ), its central northeast India subdivision of East Uttar Pradesh $\left(26^{\circ} \mathrm{N}, 82^{\circ} \mathrm{E}\right)$, and the individual station record at Lucknow, India $\left(27^{\circ} \mathrm{N}, 81^{\circ} \mathrm{E}\right)$. Rainfall from this core region is considered a particularly sensitive index of largescale monsoonal convective activity, not only over India but extending eastward over $10-30^{\circ} \mathrm{N}, 70-110^{\circ} \mathrm{E}$, including Myanmar [Goswami et al., 1999]. We also compared the teak chronology to sea surface temperature (SST) data [Kaplan et al., 1998], and indices of the El Niño-Southern Oscillation (ENSO); analyses performed in KNMI Climate Explorer (http://www.knmi.nl/).

\section{Results}

[10] In relatively dry central Myanmar, rainfall is typically lowest from November to April, while the wet (southwest)

\footnotetext{
${ }^{1}$ Auxiliary materials are available in the HTML. doi:10.1029/ 2011 GL049927.
}

monsoon season extends from around May to October. A plot of gridded monthly temperature and rainfall for this region (Figure S2 in the auxiliary material) illustrates the pronounced seasonality that stimulates annual growth rings to form in teak, as has been well demonstrated for several other locations and tree species in the tropics of Asia [Buckley et al., 2007; 2010; D'Arrigo and Smerdon, 2008; Cook et al., 2010].

[11] Monthly correlations between the Myanmar teak ringwidth chronology (Figure 2) and instrumental PDSI [Palmer, 1965; Dai et al., 2004] (1950-2003) were computed for the gridded region overlapping our teak site from $15-25^{\circ} \mathrm{N}$ and $95-105^{\circ} \mathrm{E}$, spanning the period from the year prior to growth to the current year (Figure S3 in the auxiliary material). Statistically significant (95\% level or higher), positive correlations were found for the months concurrent and just prior to the wet monsoon season, from around April to August (Figures S2 and S3 in the auxiliary material). Correlations with PDSI are strongest when averaged over May and June (r 0.32, 0.02, n 54), reflecting the importance of moisture availability for teak growth in central Myanmar around the time of monsoon onset. Comparison with local monthly station rainfall records further confirms that teak growth in central Myanmar is moisture-limited. For example, rainfall averaged over Mar-June from the city of Yangon (Figure 1) significantly and positively correlates with teak growth $(\mathrm{r}=.38,0.001, \mathrm{n} 68)$.

[12] The Myanmar teak ring-width chronology also shows significant correspondence with larger-scale indices typically used to represent Indian and south Asian monsoon rainfall. With the IITM All-India monsoon rainfall index, correlation for May-June is $\mathrm{r}=0.36,0.01, \mathrm{n}$ 57). Correlations are stronger using the core northeast Indian monsoon rainfall index, which represents the region of India opposite the Bay of Bengal from Myanmar $\left(23^{\circ} \mathrm{N}, 76^{\circ} \mathrm{E}\right.$, Figure 2, bottom): averaged over Jan-June (1950-2006), the correlation is $r=$ 0.46, 0.001, n 57). For East Uttar Pradesh, a subdivision of this core region, the correlation is 0.47 since 1950 (Jan-July, $0.001, \mathrm{n} 57)$; and $\mathrm{r}=0.29$ over the maximum common period $\left(0.001, \mathrm{n} 136,26^{\circ} \mathrm{N}, 82^{\circ} \mathrm{E}\right.$ (Figures 1 and 2, bottom).

[13] The Myanmar teak series correlates negatively with Niño-3 SST (Jul-Aug, r -0.27, 0.05, n 60), consistent with the tendency for positive Niño-3 SSTs, as during El Niño warm events, to be linked to drought conditions and decreased teak growth over southeast Asia, due to the eastward migration of the Walker circulation. Previously, a negative relationship between ENSO and (Jun-Sep) Myanmar precipitation patterns was found for central Myanmar: $\mathrm{r}=-0.68$ over 1951-2002 [Sen Roy and Sen Roy, 2011]. Notably, Myanmar teak growth in the year 1999, following the so-called El Niño of the Century of 19978 (http://www.knmi.nl/ oldenbor/publ/bien/), is the most narrow year on record (tree-ring index value is $0.40 \mathrm{vs}$. longterm mean of 1.0, normalized value -2.4 , Figure 2 ). The year 1998 also shows the lowest annual rainfall value on record for central Myanmar and vicinity (averaged over $15-25^{\circ} \mathrm{N}$, $95-105^{\circ} \mathrm{E}$, Vasclim rainfall, 1952-2000, normalized value -2.07 , Figure 2); which correlates with Jan-Jun Niño3 SST at $r=-0.54,0.0000, \mathrm{n} 57$. There may also be some modulating effect from the PDO that is spatially variable across Myanmar [Sen Roy and Sen Roy, 2011]. The teak record and the PDO correlate with each other at $\mathrm{r}=-0.34$ (Jan-Jun, 0.001, n 110). Correlation of the teak record with 


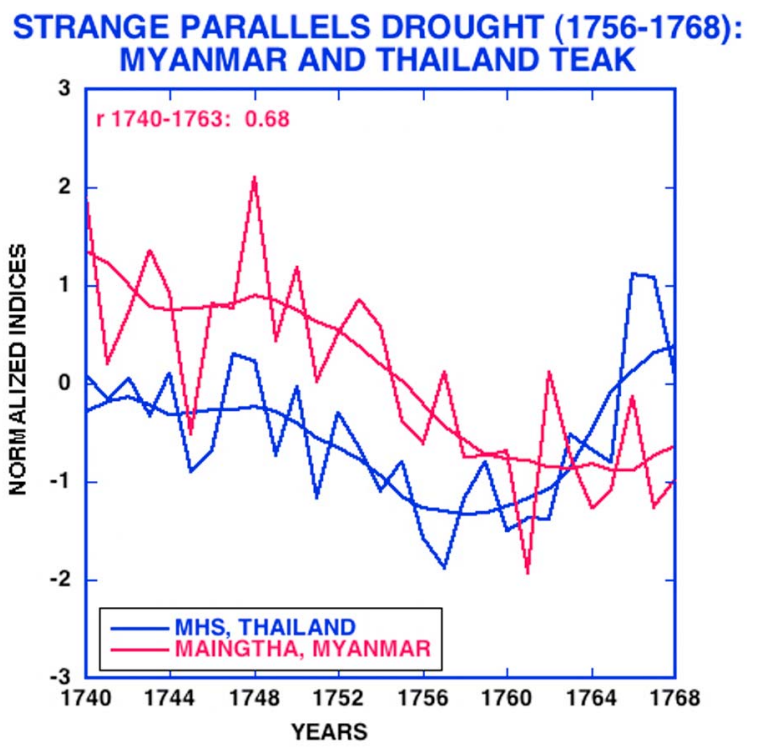

Figure 3. Comparison of teak ring width chronologies for Maingtha Reserve Forest, Myanmar (this study) and Mae Hong Son, Thailand [Buckley et al., 2007, 2010] during the period of so-called "Strange Parallels" megadrought [Leiberman, 2003; Cook et al., 2010]. Good agreement in this comparison supports other observations of a major megadrought at this time that coincided with societal collapse in many areas of southeast Asia.

GHCN/CAMS surface air temperatures north and west of India $\left(65-85^{\circ} \mathrm{E}, 30-40^{\circ} \mathrm{N}\right)$ is $\mathrm{r} 0.53$ for May-July $(0.000$, $\mathrm{n}$ 62). This pattern may reflect the long-term postulated association between Eurasian temperatures and the monsoon [Kumar et al., 1999].

[14] The most pronounced spectral peak over 1700-2009 for the Myanmar chronology is observed at 38-68 years (99\% level), with secondary peaks at $\sim 27$ years (95\% level), and 2-4 years (99\% level) (Figure S4 in the auxiliary material). Previous studies, based on instrumental Myanmar rainfall data for much shorter intervals (decades to past century), similarly noted 2-6 year periodicities indicative of the quasi-biennial oscillation (QBO) and ENSO (R. Robinson, personal communication, 2010), as is typically found in aspects of the Asian monsoon system [Kumar et al., 1999].

[15] The Mae Hong Son (MHS) teak record from adjacent Thailand [Buckley et al., 2007] (Figure 1) shows evidence for decadal to multidecadal-scale so-called megadroughts over the past several centuries (e.g., in the early and middle 1700s). These events are also seen in speleothem isotopic data from Dandak Cave [Sinha et al., 2011; also see Sachs et al., 2009], in the core region of India, that have been attributed to possible shifts in the Intertropical Convergence Zone (ITCZ) that may impact break spells of the monsoon $\left(19^{\circ} \mathrm{N}, 82^{\circ} \mathrm{E}\right)$. Correlations between the Myanmar and MHS tree-ring series, while weak overall, are most strongly positive during two overlapping intervals coinciding with megadrought-type conditions at MHS. For the first interval, from 1690-1714, the two teak series correlate at $\mathrm{r}=0.49$. The local minimum during this megadrought period is in 1703 at MHS (ring width index 0.63), while the value in the Myanmar teak record is 0.50 (both chronology values based on a long-term mean of 1 ; normalized values, based on 1617-2005 base period: MHS (-2.7), and Myanmar (-2.0). The second drought interval, from $\sim 1756-1768$, overlaps the so-called "Strange Parallels" drought, one of the most important periods of monsoon drought evidenced in the MADA tree-ring network [Leiberman, 2003; Cook et al., 2010] (Figure 3). For 1740-1763, $\mathrm{r}=0.68$ between the Myanmar and MHS teak series.

[16] Myanmar teak growth is also below average during the late Victorian Great Drought, which was associated with a major ENSO warm event (1876 to 1878), perhaps the most spatially pervasive and severe drought in the MADA [Cook et al., 2010]. For these three years, Maingtha teak normalized values are $-0.70,-0.94$ and -0.92 (average -0.85 ). For MHS, the index values are $-0.95,-1.34$, and -0.44 (ave -0.91). The Myanmar teak shows near-normal values during the famed East India drought of 1790 to 1796, which was also not particularly strong in the MADA [Cook et al., 2010]. The spectral peaks identified above for the Maingtha site are similar to those identified for MHS, Thailand (Figure 1), which has its strongest peaks at 2-4 and 48.5 years, the former considered likely related to ENSO.

\section{Discussion and Conclusions}

[17] Improved knowledge of the considerable complexities of long-term Asian monsoon fluctuations over Myanmar and vicinity requires additional coverage and analysis of paleoclimatic data. Herein, we have described a teak tree-ring width chronology for central Myanmar that is one of the first such records to be published for this country. This record is significantly and positively correlated with local to regional precipitation for Myanmar as well as with larger scale indices of Indian monsoon core rainfall, particularly over northeastern India. The Myanmar teak also correlates positively with Eurasian temperatures (suggestive of a proposed link with the Asian monsoon) and negatively with Niño-3 SST, consistent with the tendency for El Niño warm events to be linked to drought over southeast Asia (e.g., following the noteworthy 1997-98 warm event). This teak record thus reveals the regional to large-scale climatic influence on local climate in Myanmar as reflected in the tree-ring data. Inferred drought conditions coincide temporally with megadroughts identified elsewhere in southeast Asia, including Thailand and Vietnam [Buckley et al., 2007, 2010], previously attributed to variability in the tropical Indo-Pacific climate system and the ITCZ. Somewhat surprisingly, our analyses did not indicate particularly strong relationships with indices of Indian Ocean climate, such as the Indian Ocean Dipole Mode, despite significant relationships of such indices with climate over land areas elsewhere along the Indian Ocean rim [Leiberman, 2003]. Overall, our results indicate the significant potential for generating reconstructions of monsoon climate dynamics for Myanmar and vicinity from tree-ring data. Such records can be used to help unravel the many remaining questions regarding the variability and complex nature of the greater Asian monsoon system.

[18] Acknowledgments. This project was funded by the National Science Foundation Paleoclimate and Earth System History programs, grant OCE 04-02474. CCU gratefully acknowledges financial support from the Australian Research Council and the Australian Academy of Science through their Scientific Visits to North America Program. We also gratefully acknowledge the assistance and cooperation of our colleagues at the Forest Research Institute, Yezin, Myanmar. We thank Z. Myint for assistance with fieldwork, P. Fenwick for processing of tree-ring data, and B. Buckley for 
use of the MHS data. Lamont-Doherty Earth Observatory contribution 7510 R. D'Arrigo developed the idea for the manuscript, wrote the paper and conducted analyses. J. Palmer cowrote the paper, conducted analyses and conducted fieldwork. C. Ummenhofer cowrote the paper, conducted analyses and drafted figures. N. N. Kyaw cowrote the paper and provided logistical assistance. P. Krusic assisted with fieldwork and logistics.

[19] The Editor thanks the two anonymous reviewers for their assistance in evaluating this paper.

\section{References}

Beck, C., and J. Grieser (2005), Variability analyses of surface temperature observations (VasclimO), German Weather Serv., Offenbach, Germany.

Buckley, B., K. Palakit, K. Duangsathaporn, P. Sanguantham, and P. Prasomsin (2007), Decadal scale droughts over northwestern Thailand over the past 448 years: Links to the tropical Pacific and Indian Ocean sectors, Clim. Dyn., 29, 63-71, doi:10.1007/s00382-007-0225-1.

Buckley, B., et al. (2010), Climate as a contributing factor in the demise of Angkor, Proc. Natl. Acad. Sci. U. S. A., 107, 6748-6752, doi:10.1073/ pnas.0910827107.

Cook, E. (1985), A time series analysis approach to tree-ring standardization, Ph.D. thesis, Univ. of Ariz., Tucson.

Cook, E., and L. Kairiukstis (1990), Methods of Dendrochronology, Kluwer, Dordrecht, Netherlands.

Cook, E., K. Briffa, D. Meko, D. Graybill, and G. Funkhouser (1995), The 'segment length curse' in long tree-ring chronology development for paleoclimate studies, Holocene, 5, 229-237, doi:10.1177/ 095968369500500211.

Cook, E., et al. (2010), Asian monsoon failure and megadrought during the last Millennium, Science, 328, 486-489, doi:10.1126/science.1185188.

Dai, A., K. Trenberth, and T. Qian (2004), A global data set of Palmer Drought Severity Index for 1870-2002: Relationship with soil moisture and effects of surface warming, J. Hydrometeorol., 5, 1117-1130, doi:10.1175/JHM-386.1.

D'Arrigo, R., and J. E. Smerdon (2008), Tropical climate influences on drought variability over Java, Indonesia, Geophys. Res. Lett., 35, L05707, doi:10.1029/2007GL032589.

Fan, Y., and H. van den Dool (2008), A global monthly land surface air temperature Analysis for 1948-present, J. Geophys. Res., 113, D01103, doi:10.1029/2007JD008470.

Friedman, J. (1984), A variable span smoother, Tech. Rep. LCS5, Dep. of Stat., Stanford Univ., Stanford, Calif.

Gadgil, S. (2003), The Indian monsoon and its variability, Annu. Rev. Earth Planet. Sci., 31, 429-467, doi:10.1146/annurev.earth.31.100901.141251.

Goswami, B., V. Krishnamurthy, and H. Annamalai (1999), A broad-scale circulation index for the interannual variability of the Indian summer monsoon, Q. J. R. Meteorol. Soc., 125, 611-633, doi:10.1002/ qj. 49712555412 .

Kaplan, A., M. A. Cane, Y. Kushnir, A. C. Clement, M. B. Blumenthal, and B. Rajagopalan (1998), Analyses of global sea surface temperature
1856-1991, J. Geophys. Res., 103, 18,567-18,589, doi:10.1029/ 97JC01736.

Kondoh, A., A. Harto, R. Eleonora, and T. Kojiri (2004), Hydrological regions in monsoon Asia, Hydrol. Processes, 18, 3147-3158, doi:10.1002/ hyp. 5754

Kumar, K., B. Rajagopalan, and M. Cane (1999), On the weakening relationship between the Indian monsoon and ENSO, Science, 284, 2156-2159, doi:10.1126/science.284.5423.2156.

Leiberman, V. (2003), Strange Parallels: Southeast Asia in Global Context, C. 800-1830, vol. 1, Integration on the Mainland, Cambridge Univ. Press, Cambridge, U. K.

Palmer, W. C. (1965), Meteorological drought, Weather Bur. Res. Pap. 45, U.S. Dep. of Commer., Washington, D. C.

Parthasarathy, B., A. Munot, and D. Kothawale (1994), All India monthly and seasonal rainfall series: 1871-1993, Theor. Appl. Climatol., 49, 217-224, doi:10.1007/BF00867461.

Pumijumnong, N., D. Eckstein, and W. Park (2001), Teak tree-ring chronologies in Myanmar: A first attempt, Palaeobotanist, 50, 35-40.

Sachs, J. P., D. Sachse, R. Smittenberg, Z. Zhang, D. Battisti, and S. Golubic (2009), Southward movement of the Pacific intertropical convergence zone AD 1400-1850, Nat. Geosci., 2, 519-525, doi:10.1038/ngeo554.

Sen Roy, N., and S. Kaur (2000), Climatology of monsoon rains of Myanmar (Burma), Int. J. Climatol., 20, 913-928, doi:10.1002/10970088(20000630)20:8<913::AID-JOC485>3.0.CO;2-U.

Sen Roy, S., and N. Sen Roy (2011), Influence of Pacific Decadal Oscillation and El Niño-Southern Oscillation on the summer monsoon precipitation in Myanmar, Int. J. Climatol., 31, 14-21, doi:10.1002/joc.2065.

Sinha, A., et al. (2011), A global context for megadroughts in monsoon Asia during the past millennium, Quat. Sci. Rev., 30, 47-62, doi:10.1016/j.quascirev.2010.10.005.

Wigley, T. M. L., K. Briffa, and P. Jones (1984), On the average value of correlated time series, with applications in dendroclimatology and hydrometeorology, J. Clim. Appl. Meteorol., 23, 201-213, doi:10.1175/15200450(1984)023<0201:OTAVOC $>2.0$.CO;2.

Worbes, M. (2002), One hundred years of tree-ring research in the tropicsA brief history and an outlook to future challenges, Dendrochronologia, 20, 217-231, doi:10.1078/1125-7865-00018.

R. D'Arrigo, Tree-Ring Laboratory, Lamont-Doherty Earth Observatory, Earth Institute at Columbia University, 61 Rte. 9W, Palisades, NY 10964, USA. (rdd@ldeo.columbia.edu)

P. Krusic, Bert Bolin Centre for Climate Research, Stockholm University, SE-106 91 Stockholm, Sweden. (paul.krusic@natgeo.su.se)

N. N. Kyaw, Natural Resources Division, Forest Department, FRI Compound, 05282 Yezin, Nay Pyi Taw, Myanmar. (nnkforest@gmail.com) J. Palmer, Gondwana Tree-Ring Laboratory, PO Box 14, Little River, Banks Peninsula, Canterbury 8152, New Zealand. (gondwanadendro@gmail. com)

C. C. Ummenhofer, Climate Change Research Centre, University of New South Wales, Sydney, NSW 2052, Australia. (c.ummenhofer@unsw.edu.au) 